\title{
An Examination of the Validity and Reliability of the Turkish Version of the Nurses' Attitudes toward Obesity and Obese Patients (Natoops) Scale
}

\author{
Tuğba Meneklii ${ }^{1}$, Yasemin Yildirim ${ }^{2}$ and Çiçek Fadiloğlu ${ }^{3}$ \\ ${ }^{1}$ Harran University, School of Health, Turkey \\ ${ }_{2}^{2}$ Internal Medicine Nursing Department, Turkey \\ ${ }^{3}$ Internal Medicine Nursing Department, Turkey \\ *Corresponding author: Tugba Menekli, Assistant Professor, Viransehir College of Health Şanlıurfa, Turkey 63125
}

Submission: 㴆 December 08, 2017; Published: 眥 May 31, 2018

\begin{abstract}
Purpose: The aim of this study was to examine the validity and reliability of the Turkish version of the Nurses' Attitudes toward Obesity and Obese Patients (NATOOPS) Scale, and to provide a scale to be used in this area in Turkey.

Method: Forward-backward translation of the NATOOPS from English to Turkish. The translated instrument administered 360 nurses working in the internal medicine and surgery clinics of a university hospital in Izmir, Turkey. The size of the sample was arranged so as to be ten times the number of items on the scale. A Nurses' Identification Form and the NATOOP) Scale were used as instruments to collect data.

Result: Construct validity was tested by factor analysis. The Cronbachalpha coefficient the test-retest reliability coefficient and the item-total correlation were calculated. The scale was applied to 30 nurses twice, at the start and after two weeks. The views of 13 experts were sought on content validity, and their scores in the analysis were found to be compatible ( $K W=0.159, \mathrm{p}=0.08$ ). The Cronbachalpha coefficient obtained for the whole scale was 0.92 . In the item analysis, the item-total correlation coefficient of items on the scale varied between 0.46 and 0.91 , and no item was removed from the scale as a result. When test-retest was applied to test the invariability of the scale over time, a single factor was obtained explaining $74.17 \%$ of the total variance of the scale
\end{abstract}

Conclusion: The results of the study showed the NATOOPS Scale was an instrument of high validity and reliability for Turkish society.

Keywords: Obesity; Nurse; Attitude; Validity; Reliability

\section{Introduction}

Obesity is a health problem whose prevalence is steadily increasing in the world, particularly in developed countries. The World Health Organization (WHO) has identified an increase in the amount of fat in the composition of the body at a sufficient level to have a negative effect on health [1]. The diagnosis and treatment of obesity without the presence of any other illness is at the head of policies to protect health because of the morbidity and mortality caused by such great health problems as type 2 diabetes mellitus (DM), hypertension, dyslipidemia, and cardiovascular diseases[2,3]. Obesity is most particularly seen among the middle and low income areas of developed countries and the middle and high income areas of developing countries, but it appears widely in the whole world and its frequency is increasing [4].

In a study of the obesity profile of Turkey by the Obesity Research Association of Turkey in six provinces between 2000 and
2005 on 13,878 individuals over the age of 20,4255 individuals $(30.9 \%)$ were found to have a BMI of $>25 \mathrm{~kg} / \mathrm{m}^{2}$ [5]. This is seen in every age group, but it reaches a peak in those of middle age, and begins to decline after the age of 55. Obesity is more often seen in females, but the overweight level in men is higher. Prevalence has been seen to rise in both sexes in the period after marriage. Studies have shown an increase in the frequency of obesity of 10$40 \%$ in all countries in the past ten years, which suggests that we are faced with an epidemic of obesity in the world [6,7]. The level of occurrence of such conditions as cardiovascular disease, diabetes and hypertension are particularly high in obese adults. Also, obesity can expose various infectious diseases in adults. Alongside these physical health problems, obesity is a disease which can have psychological effects because being obese attracts ridicule and exclusion at all levels of society $[8,9]$. 
In obese individuals, self-confidence and self-esteem are low and body image is poor. In the workplace, the obese get fewer promotions, earn less, and they are excluded when their skills are less appreciated at work. Serious problems are seen in the quality of life in relation to the health of obese persons. Obese individuals show a tendency not to leave their homes in order not to be seen and be made fun of $[2,5,8]$. Nurses play a key role in providing information to obese patients on losing weight and in helping with obesity-related health problems or with care for the obese. However, studies have shown that health personnel, just like others in society, unfortunately show negative attitudes to obese people[10].

Studies carried out with nurses, physicians, dieticians and other health personnel have shown that most health professionals display negative attitudes to obese individuals. Obese people are seen by health professionals as lazy, unlikable, immobile, weakwilled, and without self control [11,12]. Providing nursing care for obese individuals under difficult health conditions can be stressful and tiring. If nurses wish to be effective in helping obese individuals to lose weight and in raising quality by providing impartial nursing care, they must understand nursing attitudes and work with obese people. If those providing health care hold to negative attitudes of obese individuals, the quality of the care they provide will be low, and these attitudes may hinder relations of trust between patients and nurses $[1,11,12]$. For this reason, it is of great importance that nurses' attitudes towards obese individuals should be evaluated using suitable measurements. Watson have developed a scale to evaluate nurses' attitudes to the obese which is applied in other countries. Using this scale, the attitudes of nurses towards obese people are identified and programs are organized in accordance with this to train nurses in the care of the obese. In this country however, there is no such scale for nurses. Therefore, the aim of this study was to examine the validity and reliability of the Nurses' Attitudes toward Obesity and Obese Patients Scale in evaluating the attitudes of nurses towards obese individuals [13].

\section{Methods}

\section{Study design}

This was a cross-sectional descriptive study.

\section{Setting and sample}

The study sample consisted of 360 nurses (ten times the number of items on the scale) who were working in the internal medicine and surgical clinics of a university hospital in Izmir, Turkey, between 5 June and 5 October 2012.

\section{Ethical consideration}

All the respondents were informed of the objectives of the study and consented to participation. Ethical approval of the study was granted by the institutional review board of Ege University
(EIRB no. -2012-50), to which one of the researchers is affiliated. The board confirmed that the study did not violate human rights, and that all contents and processes conformed to the conduct of appropriate research ethics.

\section{Instruments}

In gathering research data, a Nurses' Identification Form and the Nurses' Attitudes toward Obesity and Obese Patients Scale were used.

\section{Nurses' identification form}

This was a data collection form consisting of 12 questions. It was prepared by the researchers by scanning the literature $[4,5,8,9]$. The form included questions on the identifying characteristics of individuals, their experience in caring for obese people, and their experience of working with obese people.

\section{The nurses' attitudes toward obesity and obese patients scale}

This scale was developed by Watson, but had not previously been adapted for other countries. It evaluates the difficulties experienced by nurses and their attitudes when providing care for obese individuals. The scale consists of 36 items and five subdimensions. The first sub-dimension (14 items) evaluates what nurses feel towards obese individuals, the second (nine items) the characteristics of obese people, the third sub-dimension (eight items) the factors contributing to the control of obesity, the fourth sub-dimension (two items) the stereotypes of obese people, and the fifth sub-dimension (three items) support roles in the care of obese patients. There are no negatively scored statements in the scale. Each item scores from 0 to 5 , so that the total score is between 0 and 180 . High scores on the scale indicate a better attitude towards obese individuals. The nurses' attitude levels are evaluated according to their scores on each sub-dimension. It is reported that the total reliability coefficient of the scale is 0.81 [13]. Written permission to use the scale was obtained from the writers.

\section{Data collection and procedure}

The primary investigator obtained approval to access participants from course directors. Then, research assistants visited participants and informed them of the purpose and procedure of the study. Those who agreed to participate in the study completed the questionnaires. Those who wanted to attend the retest were asked to remember the random number on the initial questionnaire and write down the same number on the retest questionnaire. Those who did not remember the number correctly did not attend there test.

\section{Data analysis}

Data analysis was performed by computer using the programs SPSS and LISREL (Table 1) add [14,15].

Table 1: Statistical methods used in data analysis.

\begin{tabular}{|c|c|}
\hline \multicolumn{1}{|c|}{ Characteristic Examined } & Statistical Method \\
\hline $\begin{array}{c}\text { Socio-demographic characteristics analysis Compatibility analysis } \\
\text { of expert views test-retest compatibility analysis of scale and sub- } \\
\text { dimensions }\end{array}$ & $\begin{array}{c}\text { Frequency distribution, percentage, mean Kendal W analysis t test in } \\
\text { dependent groups }\end{array}$ \\
\hline
\end{tabular}


Item-total score analysis for scale and sub-dimensions Internal consistency of scale and sub-dimensions Item-factor relation

To decide on whether scale data is homogeneous and whether it is appropriate to carry out factor analysis To determine the consistency between responses

\section{Result}

The mean age of the nurses was $27 \pm 2.4,50.1 \%$ were single, $81.3 \%$ were university graduates, and $39.6 \%$ were working under contract. According to the nurses' statements, $61 \%$ of them had had no training concerning care of the obese, $75.5 \%$ had had difficulty in providing care for obese individuals, $71.2 \%$ did not want to provide care to obese individuals, and $60.7 \%$ needed special training to care for obese individuals [5].

\section{Findings relating to validity}

For the content validity of the scale, the experts' views were evaluated with the Kendall W test. In order to test structural validity, Confirmatory Factor Analysis was performed.

Language validity: In the work to adapt the Nurses' Attitudes toward Obesity and Obese Patients Scale to Turkish culture, it was first translated from English to Turkish by six people, one of whom was a language expert who knew both languages and five of whom were experts on the subject. Later, parts of this translation which coincided and parts which did not coincide were considered. After selecting the most suitable expressions for the scale items, this translation was translated back into English by one English language expert and five experts in the subject whose mother language was Turkish, who knew both languages, and who had not seen the original English version of the scale. In this way, the Turkish version of the scale was created [6].

Content validity: The language validity of the scale was evaluated by correlation of the expert views and the scores obtained from the scale. For content validity of the Turkish form so created, the degree of measurement of each item was evaluated
Pearson correlation analysis cronbach alpha coefficient factor analysis

KMO-Barlett analysis Test halving method on a scale of $0-100$ by ten experts. The resulting mean score and standard deviation were found to be $102.2 \pm 11.07$. In the Kendall Good Conformity Coefficient analysis, a value of W: 0.159 was obtained, and the conformity between the experts' views was found to be statistically significant $(\mathrm{p}>0.00)$.

Structural validity: Structural validity was evaluated by confirmatory and exploratory factor analysis. Factor analysis: In order to decide whether the scale data was homogeneous and suitable for factor analysis to be performed, KMO-Barlett analysis was conducted. As a result of this analysis, it was determined that the data was homogeneous and that the variance was suitable for factor analysis to be performed $(\mathrm{KMO}=0.91$; $\mathrm{X} 2=2086,305$; $\mathrm{p}=0.000$ ). In order to test the structural validity of the scale, factor analysis was performed on the 36 items using the principal components method and the vari max axis rotation method. As a result, five factors were found with an eigen value of more than 1 .

The scale items were gathered under five factors which explained $74.17 \%$ of the total variance (Table 2). Factor load of the sub-dimensions of the scale varied between 0.59 and 0.96 . As there was no factor among the scale items which had a factor weighting of under 0.30 , no item was taken out of the scale (Table 2 ). The conformity indices of the model obtained from confirmatory factor analysis performed for structural validity of the scale were examined, and it was found that the chi-square value $\left(\chi^{2}=820.10\right.$, $\mathrm{sd}=408, \mathrm{p}=.000$ ) was significant. Conformity index values were found to be RMSEA $=0.055$, NFI=0.98, CFI=0.98, $\mathrm{IFI}=0.95, \mathrm{RFI}=0.94$, $\mathrm{GFI}=0.92, \mathrm{AGFI}=0.93$ and $\mathrm{RMR}=0.027$. These conformity index values showed that the model gave good conformity [7].

Table 2: Results of factor analysis of the nurses' attitudes toward obesity and obese patients scale.

\begin{tabular}{|c|c|c|c|c|}
\hline Scale Sub-Dimensions & Items & $\begin{array}{l}\text { Factor Load } \\
\text { of Items }\end{array}$ & $\begin{array}{l}\text { Eigen- } \\
\text { Value }\end{array}$ & $\begin{array}{c}\text { Variance Explained by } \\
\text { Factor } \%\end{array}$ \\
\hline \multirow{7}{*}{$\begin{array}{l}\text { Factor 1: reactions to obese patients } \\
\text { (questions } 4,5,14,15,16,17,18,19 \text {, } \\
\qquad 20,21,22,23,24 \text { and } 35 \text { ) }\end{array}$} & Caring for obese patients causes discomfort. & 0.82 & \multirow{7}{*}{2.91} & \multirow{7}{*}{21.05} \\
\hline & $\begin{array}{l}\text { If nurses had a choice of patients, they would not } \\
\text { choose to care for obese patients. }\end{array}$ & 0.68 & & \\
\hline & $\begin{array}{l}\text { I feel that care given to obese patients is similar } \\
\text { to care given to non-obese patients }\end{array}$ & 0.77 & & \\
\hline & $\begin{array}{l}\text { Caring for obese patients is more irritating than } \\
\text { caring for patients of normal weight. }\end{array}$ & 0.68 & & \\
\hline & $\begin{array}{l}\text { I feel more discomfort when caring for an obese } \\
\text { patient than when caring for a patient of normal } \\
\text { weight. }\end{array}$ & 0.73 & & \\
\hline & $\begin{array}{c}\text { I feel that I am more impatient when caring for } \\
\text { an obese patient than when caring for a patient } \\
\text { of normal weight. }\end{array}$ & 0.69 & & \\
\hline & I am disgusted by caring for obese individuals. & 0.64 & & \\
\hline
\end{tabular}




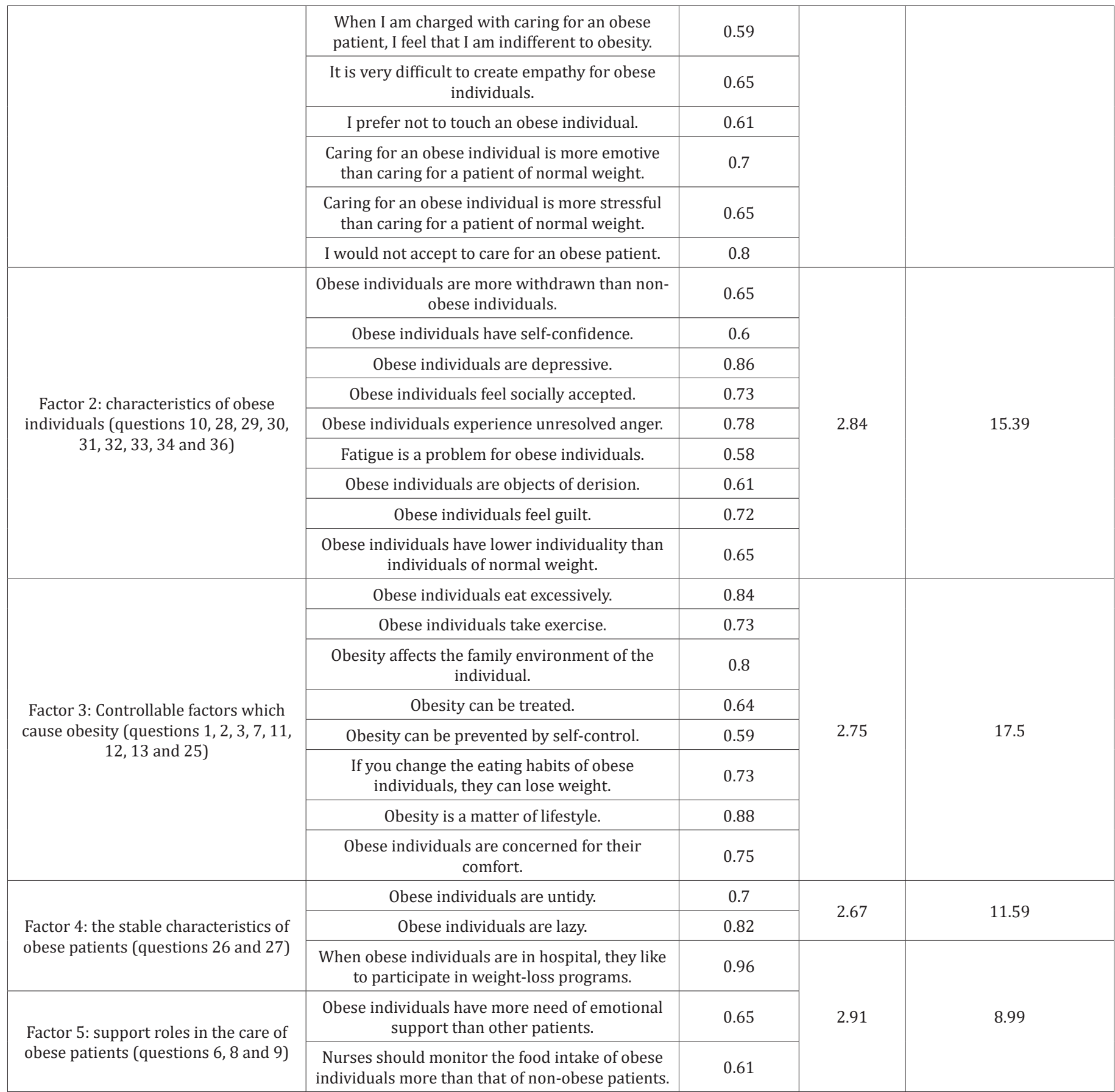

\section{Findings relating to reliability}

In the reliability analysis, Cronbach alpha analysis was used to test internal consistency. Temporal invariance of the scale and subdimensions was evaluated in dependent groups using t test (Paired Samples $\mathrm{t}$ test) and the Pearson product-moment correlation coefficient. As another reliability analysis, the Pearson productmoment correlation coefficient and item-total score correlation, sub-dimension item-sub-dimension total score correlation and sub-dimension-total score correlation coefficient were analyzed.

Internal consistency and the cronbach alpha reliability coefficient: In determining the internal consistency of the Nurses' Attitudes toward Obesity and Obese Patients Scale, the Cronbach alpha coefficient was calculated and item analysis was performed. Table 3 shows the results of the Cronbach alpha reliability analysis performed to measure the internal reliability of the Nurses' Attitudes toward Obesity and Obese Patients Scale. From this analysis, the Cronbach alpha internal consistency coefficient for the 360 nurses for the whole scale was found to be 0.92 . Internal consistency coefficients obtained for the sub-dimensions were 0.89 for the first factor (reaction to obese patients), 0.90 for the second factor (characteristics of obese individuals), 0.76 for the third factor (controllable factors which cause obesity), 0.85 for the fourth factor (stable characteristics of obese patients), and 0.81 for the fifth factor (support roles in the care of obese patients). 
Table 3: Cronbach alpha reliability coefficients.

\begin{tabular}{|c|c|c|c|c|c|}
\hline Sub-Dimensions & $\mathbf{N}$ & No of Items & Score Range & $\begin{array}{c}\text { Cronbach Alpha } \\
\text { Value }\end{array}$ & 0.89 \\
\hline $\begin{array}{c}\text { Reactions to obese } \\
\text { patients }\end{array}$ & 360 & 14 & $9-45$ & $23.15 \pm 1.87$ & 0.9 \\
\hline $\begin{array}{c}\text { Characteristics of } \\
\text { obese individuals }\end{array}$ & 360 & 9 & $8-40$ & $19.04 \pm 3.15$ & 0.76 \\
\hline $\begin{array}{c}\text { Controllable factors } \\
\text { causing obesity }\end{array}$ & 360 & 8 & $02-10$ & $4.37 \pm 1.06$ & 0.85 \\
\hline $\begin{array}{c}\text { Stable characteristics } \\
\text { of obese patients }\end{array}$ & 360 & 3 & $03-09$ & $2.01 \pm 0.91$ & 0.81 \\
\hline $\begin{array}{c}\text { Support roles in the } \\
\text { care of obese patients }\end{array}$ & 360 & 36 & $36-180$ & $88.74 \pm 9.04$ & 0.92 \\
\hline Total & 360 & 2 & & \\
\hline
\end{tabular}

Internal consistency and item analysis: Table 4 shows the item total score correlations of the Nurses' Attitudes toward Obesity and Obese Patients Scale. The lowest item-score correlation on the

while the highest, 0.91, was that of item 23 (caring for an obese individual is more stressful than caring for an individual of normal weight). scale, 0.46, was that of item 2 (obese individuals take exercise),

Table 4: Examination of the item-total score correlation of the scale $(n=360)$.

\begin{tabular}{|c|c|}
\hline Items & Item-Total Correlation (r) \\
\hline 1. Obese individuals eat excessively. & 0.69 \\
\hline 2. Obese individuals take exercise. & 0.46 \\
\hline 3. Obesity affects the individual's family environment. & 0.66 \\
\hline 4. Nurses feel uncomfortable when caring for obese individuals. & 0.71 \\
\hline 5. If nurses had the chance to choose patients, they would prefer not to care for obese individuals. & 0.6 \\
\hline 6. When obese individuals are in hospital, they like to participate in weight-loss programs. & 0.57 \\
\hline 7. Obesity can be treated. & 0.69 \\
\hline 8. Obese individuals have a greater need for emotional support than other patients. & 0.7 \\
\hline 9. Nurses should monitor the food intake of obese individuals more than that of non-obese patients. & 0.67 \\
\hline 10. The body awareness of obese individuals is greater than that of non-obese patients. & 0.51 \\
\hline 11. Obesity can be prevented by self-control. & 0.78 \\
\hline 12. If you change the eating habits of obese individuals, they can lose weight. & 0.59 \\
\hline 13. Obesity is a matter of lifestyle. & 0.64 \\
\hline 14. I feel that care given to obese individuals is similar to care given to non-obese patients. & 0.61 \\
\hline 15. Caring for an obese individual is more irritating than caring for a patient of normal weight. & 0.82 \\
\hline $\begin{array}{l}\text { 16. When caring for an obese individual, I feel greater discomfort than when I am caring for a patient of normal } \\
\text { weight. }\end{array}$ & 0.75 \\
\hline $\begin{array}{l}\text { 17. I feel that I am more impatient when caring for an obese individual than when I am caring for a patient of } \\
\text { normal weight. }\end{array}$ & 0.77 \\
\hline 18. I am disgusted by caring for obese individuals. & 0.63 \\
\hline 19. When I am charged with caring for an obese patient, I feel that I am indifferent to obesity. & 0.89 \\
\hline 20. It is very difficult to create empathy with obese individuals. & 0.62 \\
\hline 21. I prefer not to touch obese individuals. & 0.71 \\
\hline 22. Caring for obese individuals is more emotive than caring for a patient of normal weight. & 0.67 \\
\hline 23. Caring for an obese individual is more stressful than caring for a patient of normal weight. & 0.91 \\
\hline 24. I would refuse to care for an obese patient. & 0.79 \\
\hline 25. Obese individuals care about their comfort. & 0.6 \\
\hline 26. Obese individuals are untidy. & 0.78 \\
\hline 27. Obese individuals are lazy. & 0.83 \\
\hline
\end{tabular}




\begin{tabular}{|c|c|}
\hline 28. Obese individuals have self-confidence. & 0.75 \\
\hline 29. Obese individuals are depressive. & 0.82 \\
\hline 30. Obese individuals feel socially accepted. & 0.74 \\
\hline 31. Obese individuals experience unresolved anger. & 0.56 \\
\hline 32. Fatigue is a problem for obese individuals. & 0.64 \\
\hline 33. Obese individuals are objects of derision. & 0.79 \\
\hline 34. Obese individuals feel guilt. & 0.58 \\
\hline 35. Individuals of normal weight are preferred to obese individuals at work. & 0.64 \\
\hline 36. Obese individuals have lower individuality than individuals of normal weight. & 0.87 \\
\hline
\end{tabular}

Evaluation of temporal invariables on the nurses' attitudes toward obesity and obese patients: scale: The scale was applied to 30 people at three-week intervals in order to determine reliability by the test-retest method. The test-retest reliability coefficients of the sub-dimensions of the scale were evaluated by Pearson product-moment correlation. Five sub-dimensions of the scale were shown to have a significant positive relation between their mean test scores. T test was performed in dependent groups to determine whether there was a difference between mean scores obtained in the two measurements of the sub-dimensions, and no statistically significant difference was found ( $p>0.05)$.

Correlation of sub-dimension scores on the scale and total scores: When the correlation of the total sub-dimension score obtained from each sub-dimension of the scale with the total score of the scale was examined, it was found to be 0.87 for the sub-scale of reactions to obese patients, 0.75 for characteristics of obese individuals, 0.83 for controllable factors causing obesity, 0.81 for stable characteristics of obese patients, and 0.73 for support roles in the care of obese patients [1].

\section{Discussion}

The subject of this study was the analysis of the adaptation, validity and reliability in a group of participants composed of nurses of the Turkish form of the Nurses' Attitudes toward Obesity and Obese Patients Scale. The results of the Cronbach Alpha coefficients used to test the internal consistency of the scale, the Descriptor Factor Analysis used to show the general factor structure, and the Confirmatory Factor Analysis used to test the latent structure were found to be within acceptable limits $[16,17,18]$. The adaptation of a scale written in one language for a particular population for other languages is a frequently used technique in research. However, there are certain rules that must be followed, and these have a close bearing on the validity and reliability of the research.

In particular, in translations from English, attention must be paid to the active-passive distinction, and sayings and special expressions must be translated with care (Table 4). In translations, it is more important to preserve the overall meaning than to make meaningless word-by-word translations. However, the wrong use of words and language mistakes in translation can create problems for research studies. As a result, one of the inter-cultural problems which can occur in research is the faithfulness of the translations used to the original, and these translations must be made with great care because they can directly affect the results. In work to ensure linguistic equivalence of scales, the most commonly used method is re-translation [19-22]. In the present study, the items on the re-translated scale were examined for equivalence to their original forms, and after necessary corrections by the researchers the scale was presented in its final form for expert views. After language adaptation, the views of ten experts on the topic were sought in order to evaluate the suitability and comprehensibility of the language of the scale. No statistically significant difference was found between the views of the experts (W: $0.159, \mathrm{p}=0.08$ ).

The analyses performed showed that the internal consistency of the scale was very high, and that there was selective and significant correlation between the items. Also, the results of the factor analysis indicated that the Turkish form of the scale had the same factor structure as the original form. The results of the descriptor factor analysis showed that the scale was made up of five factors and that it had the same factor structure as the original form. Generally, $40-60 \%$ variance is seen as adequate. In this study also, total variance was obtained at an adequate level. In order to test the structural validity of the scale, confirmatory analysis was performed. Confirmatory factor analysis evaluates whether the relationship between items forming a factor and the factor are adequate.

When adapting a scale developed in one culture for another culture, it is recommended that confirmatory factor analysis be used because it tests an existing hypothesis concerning the structure of items on the scale $[16,20,23]$. In this study, the factor loads of the items on the sub-dimensions of the scale were between 0.59 and 0.96 and were found to be at an acceptable level. Table 1 shows the factor loads and conformity indices of the sub-dimensions of the scale. The fact that the conformity values are 0.90 for GFI and CFI and $<0.05$ for RMSEA shows that the model is acceptable and has conformity $[23,24]$.

Reliability is a basic characteristic which any measurement instrument must have, and is the capability of a measurement instrument to make measurements which are free of error. The item-total score correlation for determining the reliability of the scale was evaluated by the internal consistency and temporal invariance methods $[17,20,24]$. The basic view which internal consistency depends on is the assumption that each measurement instrument is formed as a whole $[25,26]$, that it is formed from units which are empirically independent from each other, and that these have known and equal weighting within the whole. The 
internal consistency coefficient of the scale was found to be very reliable in five sub-dimensions. When compared with the other sub-dimensions, the lowest apha coefficient was given in the subdimension of controllable factors which cause obesity (0.76). The alpha value found in this study was close to the value of the original scale, and had a high level of reliability. The results of the analyses showed that the internal consistency and homogeneity of the Turkish form of the scale were adequate. A high correlation coefficient obtained for an item shows that the connection with the measured theoretical structure of that item is also high, and that the intended behavior of the item is effective and adequate in measurement $[19,25]$. Examining the item sub-scale total score correlations, it was found that all items of the scale gave adequate correlation with the total score of the sub-dimension where they were located. In order to determine test-retest reliability, a test is applied a second time to the same group after a certain time interval (Table 5).

Table 5: Test-retest reliability coefficients of the nurses' attitudes toward obesity and obese patients scale.

\begin{tabular}{|c|c|c|c|c|c|c|}
\hline Sub-Dimensions & $\mathbf{n}$ & $\begin{array}{c}\text { No of } \\
\text { Items }\end{array}$ & $\mathbf{r}$ & $\mathbf{p}$ & $\mathbf{t}$ & $\mathbf{p}$ \\
\hline Reactions to obese patients & 30 & 14 & 0.78 & 0 & 0.706 & 0 \\
\hline $\begin{array}{c}\text { Characteristics of obese } \\
\text { individuals }\end{array}$ & 30 & 9 & 0.81 & 0 & 1.36 & 0 \\
\hline $\begin{array}{c}\text { Controllable factors causing } \\
\text { obesity }\end{array}$ & 30 & 8 & 0.7 & 0 & 1.557 & 0 \\
\hline $\begin{array}{c}\text { Stable characteristics of } \\
\text { obese patients }\end{array}$ & 30 & 2 & 0.87 & 0 & 1.816 & 0 \\
\hline $\begin{array}{c}\text { Support roles in the care of } \\
\text { obese patients }\end{array}$ & 30 & 3 & 0.89 & 0 & 2.086 & 0 \\
\hline Total & 30 & 36 & 0.96 & 0 & 1.983 & 0 \\
\hline
\end{tabular}

Later, the correlation is found between the scores obtained by individuals on the first application of the test and their scores on its second application. The correlation coefficient obtained is the reliability coefficient of the test. Complete correlation relating to reliability, that is 1.00 , shows that there is no rank variation, while 0.00 shows that there is no relation between ranks. However, the extreme values of 1.00 and 0.00 are quite rare. While the correlation coefficient varies between -1.00 and +1.00 , reliability coefficients almost always vary between 0.00 and $+1.00[16,26,27]$. Comparison between the scores obtained from the first and second measurements in test-retest application and a lack of significant difference between the two measurements shows that the results are similar. In the present study, no statistically significant difference was found between the scores of the first application and the repeat application three weeks later. This lack of difference is an indicator that the scale is reliable. A total test-retest correlation of the scale of 0.96 shows that it is a measurement instrument of high reliability [7-15].

\section{Conclusion}

In this study, the adaptation of the Nurses' Attitudes toward Obesity and Obese Patients Scale was carried out in accordance with internationally accepted scientific methods, and the validity and reliability measurements of the Turkish form of the scale were determined and compared. The factor structure of the original and the Turkish form were found to conform and it was concluded that the scale could be used in nursing practice and research in this country[16-37].

\section{References}

1. Akgül A, Çevik O (2003) Factor Analysis, Statistical Analysis Techniques, Business Management and Applications in SPSS, New Mustafa Bookstore, Ankara, Turkey.

2. Aksayan S, Bahar Z, Bayik A (2002) Research Principles, Processes and Methods in Nursing, Nursing Research and Development Association, $1^{\text {st }}$ (edn), Odak Ofset, Istanbul, Turkey, pp. 114-210.

3. Aksayan S, Gözüm S (2002) Guidelines for cross-cultural scale adaptation I: Scale adaptation steps and language adaptation. Journal of Nursing Research 4(1): 9-14.

4. Bagley CR, Conklin DN, Isherwood RT, Pechiulis DR, Watson LA (1989) Attitudes of nurses toward obesity and obese patients. Perceptual \& Motor Skills 68(3 Pt 1): 954.

5. Bağrıçak N, Onat H, İlhan B, Tarakci T, Oşar Z, et al. (2009) Obesity Profile in Turkey, International Journal of Diabetes and Metabolism 17: 5-8.

6. Baykul Y (2000) Validity, Reliability, Measurement in Education and Psychology, Classical Test Theory and Application, ÖSYM Publications, Ankara, Turkey, pp. 141-233.

7. Birol L (2007) Nursing Process. $8^{\text {th }}$ (edn), Impact Printing and Publishing Ltd. Sti, İzmir, Turkey, pp. 21-28.

8. Bocquier A, Verger P, Basdevant A, Andreotti G, Baretge J, et al. (2005) Overweight and obesity: Knowledge, attitudes and practices of general practitioners in France. Obesity Research 13(4): 787-795.

9. Blundell JE, Cooling J (2000) Routes to obesity: Phenotypes, food choices and activity. Br J Nutr 83(Suppl 1): 33-38.

10. Brown I (2006) Nurses' attitudes towards adult patients who are obese: Literature Review. Journal of Advanced Nursing 53(2): 221-232.

11. Büyüköztürk S (2006) Validity, Reliability. Data Analysis Handbook, Pegem A Publishing, Ankara, Turkey, 6: 167-169.

12. Cade J, O'Connell S (1991) Management of weight problems and obesity: Knowledge, attitudes and current practice of general practitioners. British Journal of General Practice 41(345): 147-150.

13. Campbell K, Crawford D (2000) Management of obesity: attitudes and practices of Australian dietitians. International Journal of Obesity 24: 701-710.

14. Clark JM, Brancati FL (2000) The challenge of obesity-related chronic diseases. J Gen Intern Med 15(11): 828-829.

15. Demirali YE (1995) Validity-reliability in scales. NS. Ataturk Education Faculty Journal of Educational Sciences 7: 125-148

16. Ercan I, Kan I (2004) Reliability and validity in scales. Journal of Uludag University Faculty of Medicine, Turkey 30(3): 211-216.

17. Erefe I (2002) Quality of Data Collection Tools. In: Erefe I (Ed.), Research Principles, Processes and Methods in Nursing, Focus Ofset, Istanbul, Turkey, pp. 169-188.

18. Ergin DY (1995) Validity and Reliability in Scales. NS. Atatürk Faculty of Education Journal of Educational Sciences 4: 125-148.

19. Garner CM, Nicol GT (1998) Comparison of male and female nurses' attitudes toward obesity. Perceptual \& Motor Skills 86(3 Pt 2): 1442.

20. Gözüm S, Aksayan S (2002) Guidelines for cross-cultural scale adaptation II: Psychometric properties and cross-cultural comparison. Journal of Research and Development in Nursing 4(2): 9-20. 
21. Harrington D (2009) Confirmatory factor analysis. Oxford University Press, New York, USA, pp. 21-99.

22. Hoppe R, Ogden J (1997) Practice nurses' beliefs about obesity and weight related interventions in primary care. International Journal of Obesity 21(2): 141-146.

23. Kalayci S (2005) SPSS Applied Multivariate Statistical Techniques. Asil Publication Distribution, Ankara, Turkey.

24. Kan A (2006) Qualifications that must be present in measurement tools. In: Atilgan $\mathrm{H}$ (Ed.), Measurement and evaluation in education. Memoir Publishing, Ankara, Turkey, pp. 88-138

25. Karasar N (2000) Scientific Research Method. $10^{\text {th }}$ (edn), Nobel Yayın Dağıtım Ltd. Sti. Ankara, Turkey, pp. 136-153.

26. Maroney D, Golub S (1992) Nurses' attitudes toward obese persons and certain ethnic groups. Perceptual \& Motor Skills 75(2): 387-391.

27. Oner N (1994) Psychological tests with proven reliability and/or validity. Turkish Journal of Psychology Special Issue, Psychological Tests 6(33): 9-18.

28. Ozdamar K (2004) Statistical Data Analysis with Package Programs. Extended $5^{\text {th }}(\mathrm{edn})$, Kaan Publishing House, Eskisehir, Turkey, pp. 661673.

29. Ozturk S (2006) Some Statistics Used in Validity and Reliability Analysis of Tests, $6^{\text {th }}$ (edn), Data Analysis Handbook for Social Sciences, Pegem A Publishing, pp. 167-182.
30. Perri MG, Corsica JA (2002) Improving the maintenance of weight loss in behavioral treatment of obesity. In: Wadden TA, Stunkard AJ (Eds.), Handbook of Obesity Treatment, Guilford Press, New York, USA 357379.

31. Sümbüloğlu V, Sümbüloğlu K (2002) Research Methods in Health Sciences, $4^{\text {th }}($ edn), Hatipoğlu Press and Publication San. Trade Ltd. Sti, Ankara, Turkey.

32. Simsek OF (2007) Introduction to Structural Equation Modeling Basic Principles and Applications of LISREL. Cem web Offset, Ankara, Turkey.

33. Tavsancil E (2005) Measuring Attitudes and Data Analysis with SPSS, Nobel Yayın Dağıtım, $2^{\text {nd }}($ edn), pp. 3-58.

34. Tezbaşaran A (2004) Comparison of traditional item analysis techniques in selecting items for Likert type scales. Turkish Journal of Psychology 19(54): 77-78.

35. Velioglu P (1999) Concepts and Theories in Nursing. Alas Offset, Istanbul, Turkey.

36. Watson L, Oberle K, Deutscher D (2008) Development and Psychometric Testing of the Nurses' Attitudes Toward Obesity and Obese Patients (NATOOPS) Scale. Research in Nursing \& Health 31(6): 586-593.

37. Wood GL, Haber J (2002) Reliability and validity. In: Wood Gb, Haber (Eds.), Nursing Research Methods, Appraisal and Utilization. Mosby st. Louis, France, pp. 311-330.
Creative Commons Attribution 4.0 International License

For possible submissions Click Here

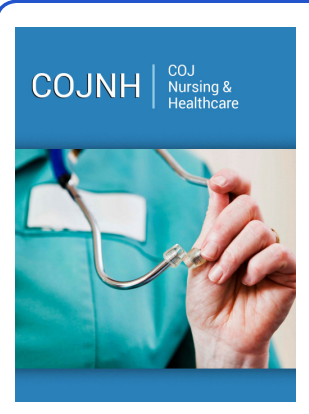

\section{COJ Nursing \& Healthcare}

\section{Benefits of Publishing with us}

- High-level peer review and editorial services

- Freely accessible online immediately upon publication

- Authors retain the copyright to their work

- Licensing it under a Creative Commons license

- Visibility through different online platforms 